\title{
Basic Economic Analysis for Sonochemical Processes
}

\author{
Carlo Pirola*
}

Dipartimento di Chimica, Via Golgi, 19 - 20133 Milano, Italy

\begin{abstract}
Ultrasound (US) and other non-traditional energy sources (for instance microwave (MW)) are widely used to increase the rate of chemical reactions, to prepare nanoparticles, to extract natural products etc. In all such cases, the scaling-up of the process must have a defined economic constraint, which generally can be reduced to the evaluation of the parameter $R_{C}$, which is the ratio between the raw energy cost to produce US (or MW) and the total production cost for unit mass of product. The paper gives a basic correlation among the different parameters to evaluate $R_{C}$ both for processes using only US (or MW and other not traditional sources) and those with mixed energy sources.
\end{abstract}

Keywords: Economic analysis, Ultrasound, Scale-up, Energy, Microwave.

\section{INTRODUCTION}

Ultrasound (US) and Microwave (MW) are energy sources largely studied to improve the efficiency of several chemical reactions, material preparations or industrial processes [1]. For example, several researches have been published proposing US as tools to promote oxidizing reactions to mineralize organic pollutants in wastewater [2]. Assisted synthesis of quinolones compounds have been reported using both MW and US to improve the yields or the selectivities [3]. The preparation of innovative heterogeneous catalysts using US in their synthesis procedure have been proposed, for example, for iron based catalysts for Fischer-Tropsch process [4]. US have been also applied to increase the performance of sorptiondesorption processes [5-7].

Nevertheless, in almost all these researches and publications, the attention is placed on the chemical effects of the application of ultrasound, while little is said about the actual energy consumption and the consequent economic evaluation. On the other side, technical and sustainability analysis is a fundamental step to develop new technologies addressed to industrial applications $[8,9]$. The economic analysis is often difficult in laboratory stage because the scheme and the size of the final industrial application is not clear in these embryonal new technologies. The scale up process and design will be defined only if the proposed technology will be considered by a company, or if the academic research will go on, with specific aims to design the possible industrial layout. Basic and simple methods to evaluate the economic consequences of the application of US and MW should

*Address correspondence to this author at the Dipartimento di Chimica, Via Golgi, 19 - 20133 Milano, Italy; Tel: ++39/0250314283; Fax: ++39/0250314300; E-mail: carlo.pirola@unimi.it estimate these important aspects in the first step of these researches and address the selection of the most important operative parameters, as first of all the ratio between US and MW power and the volume of the reactor for the different processes.

The economical incidence of the energy cost over the total cost of a chemical process is a fundamental topic in the industrial economy. In the processes in which ultrasound are applied, this evaluation is of particular importance due to the energy consumption of the US apparatus. This incidence can be of high impact over the total process cost, especially in case of low efficiency of the sonochemical sources. In this paper, a general calculation scheme is shown that is applicable to every energy consuming source. Selected numerical examples are reported using the data deriving from literature. Some hypotheses have been made and discussed both to simplify the calculations in a first approach and to uniform the data available in the US literature.

\section{DISCUSSION AND RESULTS}

The parameter $R_{C}$ indicates the ratio between the incidence of US energy cost over the cost for the total process, both referred to the same amount of product (in the case of a chemical process producing a substance). Such a parameter can be evaluated using the following equation:

$$
R_{C}=W_{S}\left(\frac{a}{b}\right)
$$

being: $R_{C}=$ money for US generation ( $€$ for total process $)^{-1} ; \mathrm{W}_{\mathrm{S}}=\mathrm{kWh}$ withdrawn from the electrical net for US generation (kg produced) ${ }^{-1} ; a=€(k W h)^{-1} ; b=$ Total $€(\mathrm{~kg} \text { produced })^{-1}$. Obviously: 


$$
W_{S}=W_{S}^{\prime} / \eta
$$

where: $W_{s}=(\mathrm{kW}$ emitted at the tip) (process time $(\mathrm{h}))$ $(\mathrm{kg} \text { of substance produced })^{-1} ; \eta=$ efficiency of US apparatus $=\mathrm{kWh}$ emitted at the tip ( $\mathrm{kWh}$ withdrawn at the electrical net) ${ }^{-1}$. Then:

$$
R_{C}=\left(\frac{W_{S}^{\prime}}{\eta}\right) x\left(\frac{a}{b}\right)
$$

We can consider as example: $W_{s}^{\prime}=10^{-3} \mathrm{kWh} \mathrm{kg}^{-1} ; \eta$ $=1\left(\right.$ then $\left.\mathrm{W}_{\mathrm{S}}=10^{-3} \mathrm{kWh} \mathrm{kg}^{-1}\right) ; \mathrm{a}=0.1 €\left(\mathrm{kWh}^{-1} ; \mathrm{b}=5\right.$ $€ \mathrm{~kg}^{-1}$, then from equations (1) and (2) it can be derived: $R_{C}=2 \times 10^{-5}$. But if the efficiency of the sonochemical apparatus is $\eta=0.5$ then $W_{S}=10^{-3} / 0.5=$ $2 \times 10^{-3} \mathrm{kWh} \mathrm{kg}^{-1}$ and $\mathrm{E}_{\mathrm{C}}=4 \times 10^{-5}$. These examples are exceptionally favourable to the use of US because only a quite negligible part of the total process cost is dedicated to US. Instead, if the total process cost is dedicated to the production of US (i.e. $R_{C}=1$ ) then from equation (1), with the same values of $a$ and $b$ as previously reported, it can be derived: $1=W_{S} \times 5 / 0.1$ then $\mathrm{W}_{\mathrm{S}}=50 \mathrm{kWh}$ is withdrawn from the net to produce US (kg processed) ${ }^{-1}$. Due to the fact that the value of $\mathrm{W}_{\mathrm{S}}$ can change in a very large range, it is more convenient to express the equation (3) on logarithmic scale:

$$
-\log R_{C}=-\log \left(\frac{W_{S}^{\prime}}{\eta}\right)-\log \frac{a}{b}
$$

For example, the halogenation of aromatic hydrocarbons was studied by Mason, Lorimer and Lindley [10] using copper (II) bromide on alumina in silent and US $(20 \mathrm{kHz})$ conditions. After $60 \mathrm{~min}$ of US irradiation, the conversion of naphthalene $(A)$ into mono $(B)$ and disubstituted $(C)$ bromoderivates was complete with a ratio $B / C=97 / 3$; the same total conversion, in silent conditions, was reached after 180 minutes with a ratio $B / C=91 / 9$. The other experimental conditions were: US $42 \mathrm{~W}(\mathrm{~cm})^{-2}$; end diameter of the horn $6 \mathrm{~mm}$ (section $0.283 \mathrm{~cm}^{2}$ ); (A) weight $1.152 \mathrm{~g}$, corresponding to a total weight of $1.8832 \mathrm{~g}((\mathrm{~B})+(\mathrm{C}))$, at $97 / 3(\mathrm{~B}) /(\mathrm{C})$ molar ratio, when $(A)$ is totally converted.

Therefore: $W_{s}^{\prime}=\left[42 \mathrm{~W} \mathrm{~cm}^{-2} \times 0.283 \mathrm{~cm}^{2}\right] \times 1 \mathrm{~h}$ $11.8832 \mathrm{~g}^{2}=6.312 \mathrm{Wh} \mathrm{g}^{-1}$ or $\mathrm{kWh} \mathrm{kg}^{-1}$.

Considering equation (3) with, $\eta=30 \%, a=0.1 €$ $(\mathrm{kWh})^{-1} ; \mathrm{b}=5 € \mathrm{~kg}^{-1}$, the parameter $\mathrm{R}_{\mathrm{C}}$ is $\mathrm{R}_{\mathrm{C}}=(6.132 /$ $0.3) \times(0.1 / 5)=04088 €$ US (€ total production $)^{-1}$.

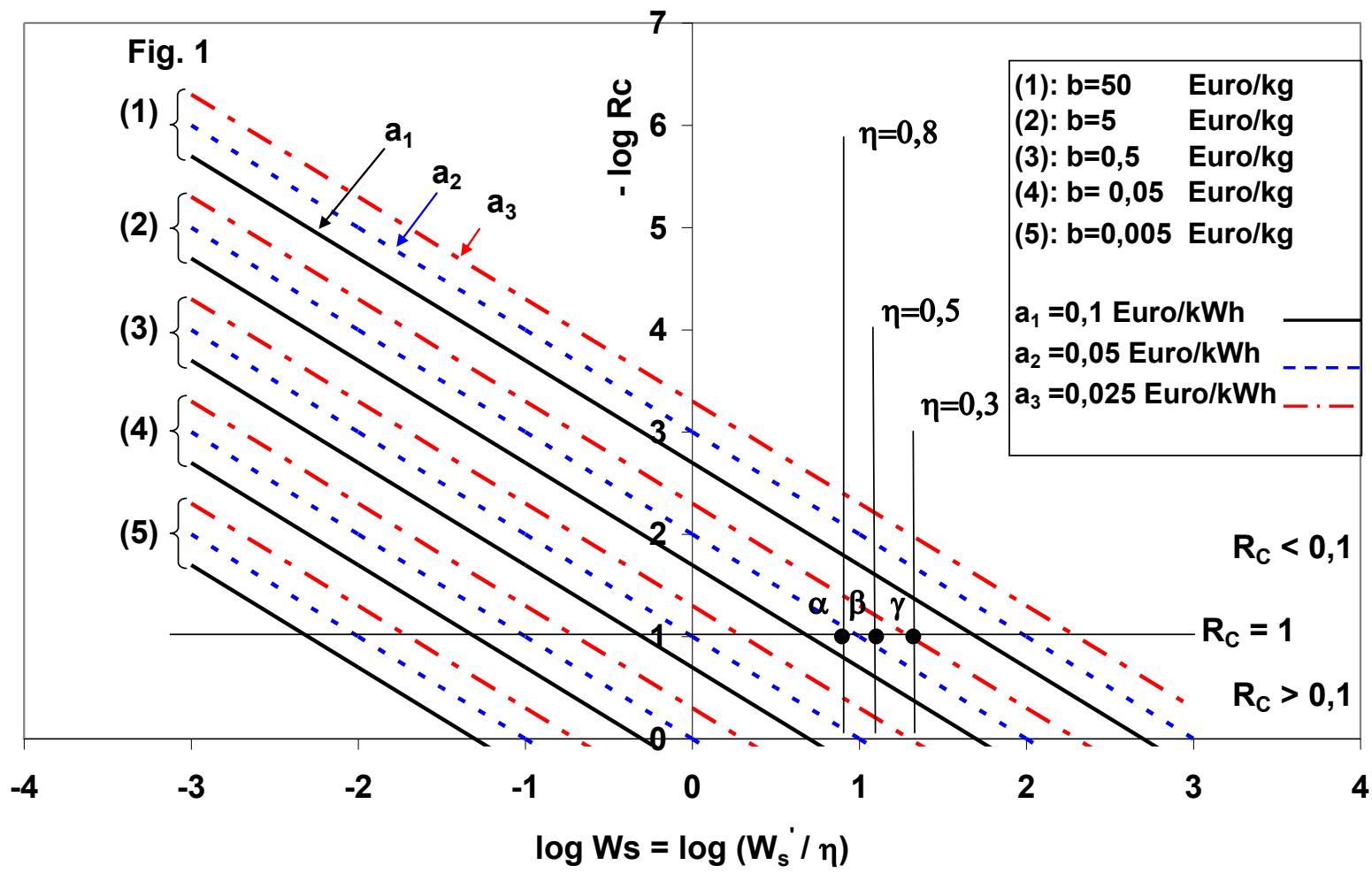

Figure 1: Graphical correlation among parameters Rc, Ws, W , $\eta, a, b$ as defined in the text. 
Obviously if the efficiency of US apparatus changes also $R_{C}$ values are different.

Therefore, it is possible to plot equation (4) for each process (i.e. for each value of $W_{s}$ ) at different values of the efficiency $\eta$ and different values of $a$ and $b$. Such results are shown on Figure 1.

For instance, by assuming $W_{s}^{\prime}=6.312 \mathrm{kWh} \mathrm{kg}^{-1}$, according to the calculations previously reported, and $\eta$ $=0.8,0.5,0.3$, the vertical lines with such values were drawn. Taking from the literature the data for $W_{s}$ (assuming $\eta=1$ ), Table 1 is derived.

Obviously, the majority of the data reported in the cited literature (Table 1 ) is on a small scale, therefore the pertinent unit for $W_{s}$ is $W h(g)^{-1}$. Therefore, the equivalence a $\left[\mathrm{Wh}(\mathrm{g})^{-1}\right]=\mathrm{a}\left[\mathrm{kWh}(\mathrm{kg})^{-1}\right]$ is absolutely correct from a formal point of view, but if applied to a chemical process, it implies that there is a linear scaleup factor that is not always correct. However, there are no indications in the literature of a scale factor at present for these kind of processes.

The reactions considered until now are characterized by a continuous emission of US or MW. Other processes can be considered in which US are used alternatively with other energy sources, or in a pulsed mode. Many of such processes are applied in industries, for example during oil extraction from the wells [18]. Taking in consideration this process, it is possible to show (Figure 2) how the quantity of oil $Q(\mathrm{~kg})$ is extracted as a function of time; usually $Q$ decreases with time due to the effect of solid deposits or very viscous hydrocarbons at the bottom of the pipes located down inside the wells.

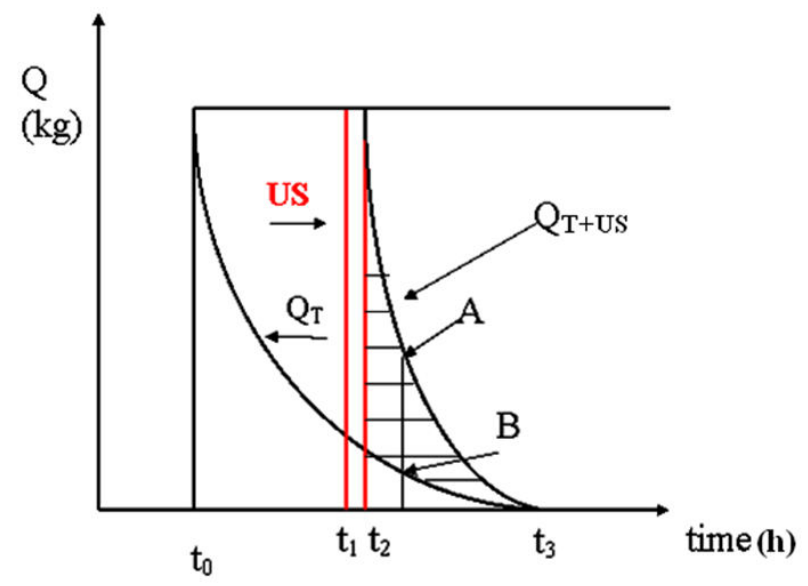

Figure 2: Productivity $Q$ as a function of time (t). $Q_{T}$ is the production applying traditional energetic sources (for instance pressure, as explained in the text), $\mathrm{Q}_{T}+\mathrm{US}$ is the production after application of US energetic source for a very short time between $t_{1}$ and $t_{2}$.

If US are emitted with a power $E_{\text {Us, near the }}$ occluded end of the pipe for a very short time, between $t_{1}$ and $t_{2}$, then the solid-viscous deposit is removed and the extraction quantity comes back to the original value. Therefore, Qus is the quantity extracted after the US treatment by using the traditional power (i.e. a source of pressure, of power $E_{T}$ ). Then, it is possible to calculate the parameter $\mathrm{W}_{\mathrm{S}}$ as:

$$
W_{S}=\frac{\int_{t_{0}}^{t_{3}} E_{T}(t) d t+\int_{t_{1}}^{t_{2}} E_{U S}(t) d t}{\int_{t_{0}}^{t_{3}} Q_{T}(t) d t+\int_{t_{2}}^{t_{3}}\left[Q_{T+U S}(t)-Q_{T}(t)\right] d t}
$$

US could be used only when $Q_{T}=0$ (Figure 3 ) from $t_{1}$ to $t_{2}$.

Table 1: Some Examples of Specific Energy Consumption (WS, $\mathrm{kWh} \mathrm{kg}^{-1}$ ) in Ultrasonic Processes Based on the Nominal Power Collected from the Net

\begin{tabular}{|c|c|c|c|}
\hline Reaction & US Frequency (kHz) & $\mathbf{W}_{\mathrm{s}}\left(\mathrm{kWh} \mathrm{kg}^{-1}\right)$ & Reference \\
\hline Alogenation of aromatic hydrocarbon & 20 & 6.31 & {$[10]$} \\
\hline Furoin alkylation & 25 & 22.7 & [12] \\
\hline Condensation between nitrobenzaldehyde and acetone & 59 & 483.9 & [13] \\
\hline Extraction of phenolic compounds from coconut & 25 & 5.83 & {$[15]$} \\
\hline Synthesis of nanocrystalline $\mathrm{HgS}, \mathrm{HgSe}, \mathrm{HgTe}$ & 20 & $\begin{array}{c}\text { HgS: } 219.6 \\
\text { HgSe: } 184.8 \\
\text { HgTe: } 160.8\end{array}$ & {$[16]$} \\
\hline $\begin{array}{c}\text { Decomposition of Volatile Solids (VS) in waste activated } \\
\text { sludge by US followed by biodegradation }\end{array}$ & 31 & $\begin{array}{l}0.1 \\
\text { (Average value) }\end{array}$ & [17] \\
\hline
\end{tabular}




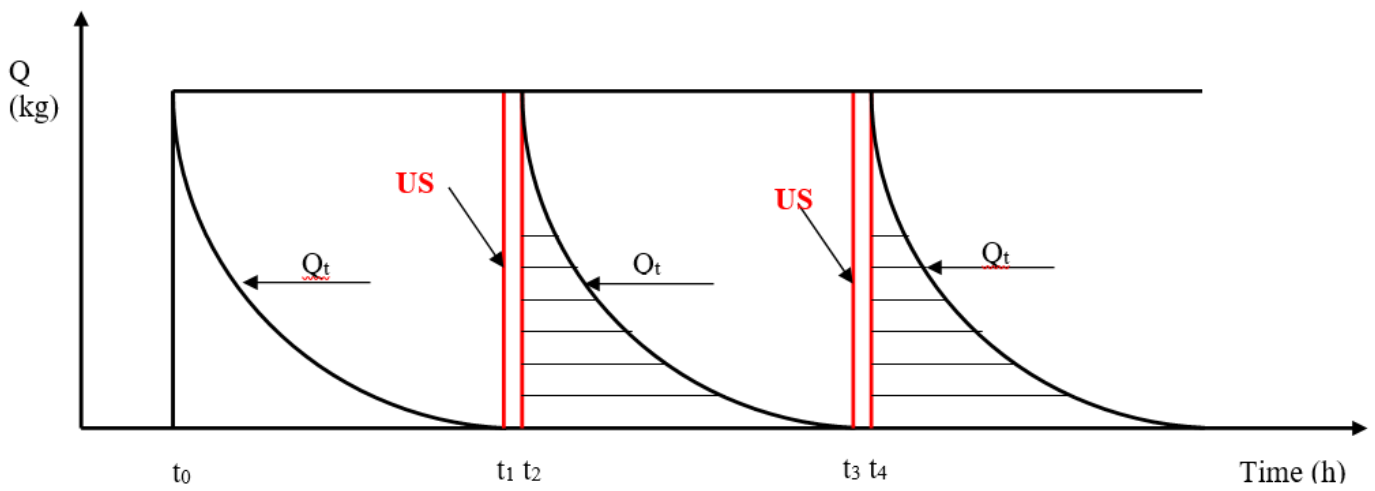

Figure 3: Cycles of productivity $Q$ by applying US for a short time between $t_{1}$ and $t_{2}$ only when the productivity $Q T$ is quite zero.

Such a treatment can be repeated cyclically in the steps II, III and so on. In this case, $\mathrm{W}_{\mathrm{S}}$ can be calculated as follows:

$$
W_{S}=\frac{\int_{t_{2}}^{t_{3}} E_{T}(t) d t+\int_{t_{1}}^{t_{2}} E_{U S}(t) d t}{\int_{t_{2}}^{t_{3}} Q_{T+U S}(t) d t}
$$

The integrals in equations 5 and 6 can be solved by interpolating with a polynomial equation, the experimental data $Q_{T}$ and $Q_{T, U S}$ vs. t.

Table 1 shows that the data of literature are extremely dispersed in order to calculate the specific energy consumption of US, $\mathrm{W}_{\mathrm{S}}\left(\mathrm{kWh}(\mathrm{kg})^{-1}\right)$, as this value ranges from $9.0 \times 10^{-3}$ to $2.5 \times 10^{-5}$. Such values are referred to very different processes and are calculated both without considering a scaling-up factor, as previously discussed, and assuming an efficiency of sonochemical apparatus $\eta=1$.

As regard to the mathematical model illustrated in the paper, the relevant parameters $W, W_{s}, a, b, \eta$, which appear in the equations 1 and 2, are easily correlated with the important economic parameter $\mathrm{R}_{\mathrm{C}}$ in a graphical form shown in Figure 1. This monogram can be used to calculate the range of flexibility of a chemical process in different forms. For instance, if $\mathrm{R}_{\mathrm{C}}$ $=0.1$ is fixed (i.e. only $10 \%$ of the production cost is dedicated to the energy- Consomption to produce US) then, according a total production cost (b), only some combinations of the electric energy cost $\left(a_{1}, a_{2}, a_{3}\right)$ are allowed each having a value of $W_{S}$, then of the efficiency of the US apparatus if a value of $W_{s}$ is required.

On the other hand, if $W_{s}^{\prime}, \eta$ and $\mathrm{b}$ are known, the energy cost has a range of variability. In Figure 1, such costs are indicated with $a_{1}, a_{2}, a_{3}$ for $W_{s}^{\prime}=6.312 \mathrm{kWh}$ $\mathrm{kg}^{-1}$ and $\eta=0.8 ; 0.5 ; 0.3$ respectively, for $\mathrm{R}_{\mathrm{C}}=0.1$. Although the above mentioned conclusions are qualitatively obvious, Figure $\mathbf{1}$ gives "quantitative" correlations among the different parameters: the lower the US apparatus efficiency is, the lower the cost of electric energy must be at a value of $W_{s}$. Conversely, in such situations ( $\eta$ low) the higher is the production cost, the lower is the value of $R_{C}$.

For hybrid processes, i.e. those using US and traditional energetic sources, the energy consumption for unit mass of the product $\left(\mathrm{W}_{\mathrm{S}}\right)$ should be determined on the basis of an elaboration of the experimental production data according to the equations (5) and (6).

\section{CONCLUSIONS}

Several processes and reactions are promoted by coupling with energetic sources such as ultrasound and microwave. A balance between the promotion given from these sources and their cost should be considered to evaluate the real economic sustainability of these processes. A simple method was proposed on the basis of the parameter $R_{C}$, which is the ratio for unit mass of product, between the raw energy cost to produce US or MW and the total production cost. The application of this parameter in different case-studies taken from literature was discussed and the main principles to define the most convenient operative parameters were suggested.

\section{REFERENCES}

[1] Cravotto G, Cintas P. The Combined Use of Microwaves and Ultrasound: Improved Tools in Process Chemistry and Organic Synthesis. Chem - A Eur J. 2007; 13: 1902-1909. doi:10.1002/chem.200601845.

[2] Pradhan SR. Colmenares-Quintero RF, Colmenares Quintero JC. Designing Microflowreactors for Photocatalysis Using Sonochemistry: A Systematic Review Article. Molecules 2019; 24: 3315.

doi:10.3390/molecules24183315. 
[3] Prajapati SM, Patel KD, Vekariya RH, Panchal SN, Patel HD. Recent advances in the synthesis of quinolines: a review. RSC Adv. 2014; 4: 24463-24476. doi:10.1039/C4RA01814A.

[4] Pirola C, Bianchi CL, Di Michele A, Diodati P, Boffito D, Ragaini V. Ultrasound and microwave assisted synthesis of high loading Fe-supported Fischer-Tropsch catalysts. Ultrason Sonochem. 2010; 17: 610-616. doi:10.1016/j.ultsonch.2009.11.004.

[5] Elwakeel KZ, Al-Bogami AS, Guibal E. 2-Mercaptobenzimidazole derivative of chitosan for silver sorption - Contribution of magnetite incorporation and sonication effects on enhanced metal recovery. Chem Eng J. 2021; 403: 126265. doi:10.1016/j.cej.2020.126265.

[6] Elwakeel KZ, Shahat A, Al-Bogami AS, Wijesiri B, Goonetilleke A. The synergistic effect of ultrasound power and magnetite incorporation on the sorption/desorption behavior of $\mathrm{Cr}(\mathrm{VI})$ and $\mathrm{As}(\mathrm{V})$ oxoanions in an aqueous system. J Colloid Interface Sci. 2020; 569: 76-88. doi:10.1016/j.jcis.2020.02.067.

[7] Elwakeel KZ, Shahat A, Khan ZA, Alshitari W, Guibal E. Magnetic metal oxide-organic framework material for ultrasonic-assisted sorption of titan yellow and rose bengal from aqueous solutions. Chem Eng J. 2020; 392: 123635. doi:10.1016/j.cej.2019.123635.

[8] Pérez L, Ledón $\mathrm{Y}$, Santana K, Domínguez E, Pérez M. Introduction of SOFC Technology into Cuban Energy Sector: Technical and Sustainability Analysis. J Chem Eng Res Updat. 2016; 2: 36-50.

doi:10.15377/2409-983X.2015.02.02.1.

[9] Vázquez-Román R, Inchaurregui-Méndez J, Ponce-Ortega J, Mannan M. A Heat Exchanger Networks Synthesis Approach Based on Inherent Safety. J Chem Eng Res Updat. 2015; 2: 22-29.

doi:10.15377/2409-983X.2015.02.01.3.

[10] Mason TJ, Lorimer JP. Practical Sonochemistry. Ellis Horwood, 1991.
[11] Brochette S, Descotes G, Bouchu A, Queneau Y, Monnier N, Pétrier C. Effect of ultrasound on KSF/O mediated glycosylations. J Mol Catal A Chem. 1997; 123: 123-130. doi:10.1016/S1381-1169(97)00038-1.

[12] Zhang F, Sun J, Gao D, Li Y, Zhang Y, Zhao T, Chen X. An efficient and convenient procedure for the synthesis of 2alkyl-2-alkoxy-1,2-di(furan-2-yl)ethanone under ultrasound in the presence of solid-liquid phase transfer catalysis conditions. Ultrason Sonochem. 2007; 14: 493-496.

doi:10.1016/j.ultsonch.2007.02.004.

[13] Ding L, Wang W, Zhang A. Synthesis of 1,5-dinitroaryl-1,4pentadien-3-ones under ultrasound irradiation. Ultrason Sonochem. 2007; 14: 563-567. doi:10.1016/j.ultsonch.2006.09.008.

[14] Wang S-X, Li Z-Y, Zhang J-C, Li J-T. The solvent-free synthesis of 1,4-dihydropyridines under ultrasound irradiation without catalyst. Ultrason Sonochem. 2008; 15: 677-680. doi:10.1016/j.ultsonch.2008.02.009.

[15] Rodrigues S, Pinto G, Fernandes F. Optimization of ultrasound extraction of phenolic compounds from coconut (Cocos nucifera) shell powder by response surface methodology. Ultrason Sonochem. 2008; 15: 95-100. doi:10.1016/j.ultsonch.2007.01.006.

[16] Kristl M, Drofenik M. Sonochemical synthesis of nanocrystalline mercury sulfide, selenide and telluride in aqueous solutions. Ultrason Sonochem. 2008; 15: 695-699. doi:10.1016/j.ultsonch.2008.02.007.

[17] Nickel K, Neis U. Ultrasonic disintegration of biosolids for improved biodegradation. Ultrason Sonochem. 2007; 14: 450-455.

doi:10.1016/j.ultsonch.2006.10.012.

[18] Bjorndalen N, Islam MR. The effect of microwave and ultrasonic irradiation on crude oil during production with a horizontal well. J Pet Sci Eng. 2004; 43: 139-150. doi:10.1016/j.petrol.2004.01.006.

Received on 23-07-2020 Accepted on 03-09-2020

Published on ??-09-2020

\section{DOI: https://doi.org/10.15377/2409-983X.2020.07.1}

(c) 2020 Carlo Pirola; Avanti Publishers.

This is an open access article licensed under the terms of the Creative Commons Attribution Non-Commercial License (http://creativecommons.org/licenses/by-nc/3.0/) which permits unrestricted, non-commercial use, distribution and reproduction in any medium, provided the work is properly cited. 